\title{
Proactive interference in retention of nondiscriminative learning'
}

DAVID A. CHISZAR ${ }^{2}$ AND NORMAN E. SPEAR, DEPARTMENT OF PSYCHOLOGY, RUTGERS UNIVERSITY, NeW Brunswick, N.J. 08903

Experiment 1 found considerable within-S recovery of an approach response previously extinguished by substitution of a quinine mixture for the initial incentive. Experiment 2 involved independent groups including controls that received only the quinine. Little change in behavior (forgetting) occurred over 60 min unless Ss had prior experience with the positive reinforcer.

\section{Problem}

Most theories of the role of interference in forgetting expect the influence of proactive interference (PI) to increase with increasing length of retention interval. If the function relating length of retention interval to magnitude of PI is similar to that relating time-since-extinction to amount of spontaneous recovery, these phenomena might be linked for explanatory purposes. However, while spontaneous recovery most of ten has been recorded after periods of minutes or hours (e.g., Kimble, 1961), PI with comparable species (lower animals) seems to require days or even weeks to exhibit influence on forgetting (e.g., Chiszar \& Spear, 1968; Koppenaal \& Jagoda, 1967; Maier \& Gleitman, 1967).

Tests of PI in lower animals usually have employed discrimination learning, while spontaneous recovery most often has been studied with classical conditioning or nondiscriminative instrumental learning. Although certain forgetting-like phenomena in nondiscriminative learning have been interpreted as consequences of PI (Spear, Hill, \& O'Sullivan, 1965; Spear, 1967; Spear \& Spitzner, 1968), these effects occurred with 24-h retention intervals. The present research was concerned with investigating PI in nondiscriminative learning after shorter intervals.

\section{EXPERIMENT I}

Subjects and apparatus. The Ss were 12 female Sprague-Dawley albino rats approximately 120 days old at the start of the experiment. All Ss had been used previously in a T-maze study which involved food-pellet reward, and had been maintained on 10 $\mathrm{g} /$ day of Purina powder for about two months including a three-day period intervening between the T-maze study and the present one. The apparatus was an unpainted cardboard box $(12 \mathrm{x}$ $12 \times 12$ in.) in one corner of which a small food cup was permanently located.

Procedure. The experiment consisted of three stages. In Stage 1 $S$ was placed in the corner of the box diagonally across from the food cup which contained wet mash (Purina powder plus water). On each trial S's latency to eat was recorded: E activated a stop watch upon releasing $S$ and stopped it when $S$ began to eat. Successive trials were separated by an intertrial interval of 10-15 sec during which $S$ was replaced in the home cage. Trials were continued until $S$ began to eat within $5 \mathrm{sec}$ after placement into the box. Stage 2 treatment was initiated approximately $15 \mathrm{sec}$ after $S$ reached Stage 1 criterion. Stage 2 treatment was identical to Stage 1, except that the food cup contained a mixture of quinine and wet mash ( 5 grains quinine sulfate per tablespoon of Purina powder). Trials during Stage 2 were continued until S's latency to eat rose to at least 25 sec. Between Stages 2 and 3, S was placed in its home cage for $1 \mathrm{~min}$. During Stage 3 (test) trials, $S$ was placed in the box with the food cup again containing quinine mash. Latency to eat was measured, and after $30 \mathrm{sec} S$ was again placed in the home cage (whether or not $S$ had tasted the wet mash). Another 30 -sec trial was given 4 min later. One h later the daily ration of food powder was given. Finally, all Ss received a third test trial $24 \mathrm{~h}$ later. Thus, latency to eat was measured 1 $\min , 5 \mathrm{~min}$ and $24 \mathrm{~h}$ after Stage 2 treatment.

Results. A mean of 2.3 trials was required to reach Stage 1 criterion. The left panel of Fig. 1 shows that between Trials 1 and 2 , the mean speed (1/latency) to eat changed from .06 to .28
( $p<.01$ by Sign Test) indicating that the presence of the reinforcer produced a significant change in Ss' behavior. A mean of 2.2 trials was required to reach the Stage 2 ("extinction") criterion. The center panel of Fig. 1 shows that between Trials 1 and 2 of Stage 2 the mean speed changed from .38 to $.06(\mathrm{p}<.01$ by Sign Test) indicating that the Ss were suppressing the tendency to eat from the food cup as a result of the quinine. The mean speeds on the three test trials are shown in the right panel of Fig. 1. Between the 1-and 5-min tests the mean speed rose from .04 to $.10(p=.055$ by Sign Test). Furthermore, the mean speed on the 24-h test (.23) was significantly greater than on the 1-min test and the 5 -min test $(p<.01$ in each case). Importantly, the speed on the 24-h test was not different from that at the end of Stage 1.

In view of the absence of the appropriate control $\mathrm{Ss}$, it is impossible to attribute the increase in speed during the retention intervals to PI. However, it appeared that more forgetting of Stage 2 occurred than expected without the prior experience with the positive reinforcer. It was the purpose of Experiment 2 to determine whether this forgetting was increased by PI.

\section{EXPERIMENT 2}

Subjects and apparatus. The Ss were 32 female Sprague-Dawley albino rats similar in age and experimental history to the Ss in Experiment 1. The apparatus was the same box used in Experiment 1.

Procedure. Treatment of Ss was generally similar to that used in Experiment 1. The Ss were divided into four groups of eight Ss per group. Two groups (the PI groups) were given treatments identical to that described for Stages 1 and 2 in Experiment 1. One of these groups was given a test trial $1 \mathrm{~min}$ after Stage 2, while the other group was tested after $60 \mathrm{~min}$. The remaining two groups (control groups) were given only the treatment appropriate to Stage 2 and were tested after 1 and $60 \mathrm{~min}$, respectively. On the retention test trials the food cup always contained the quinine-mash mixture.

Results. The PI animals required a mean of 3.1 trials to reach criterion in Stage 1. The left panel of Fig. 2 shows that between trials 1 and 2 their mean speed to eat changed from .08 to .30 $(p<.006$ by Sign Test). A mean of 2.1 trials was required by the PI Ss to reach the Stage 2 criterion, while 2.4 trials was required by control Ss. The center panel shows that between Trials 1 and 2 of Stage 2 the mean speed for the PI Ss changed from .30 to .03, and for control Ss from .10 to .03 ( $p<.01$ by Sign Test for each case), indicating that Ss were suppressing the tendency to eat from the food cup after one experience with the quinine mixture. Importantly, the Trial 1 speed of the control Ss (.10) was no slower than the initial Stage 1 speed of the PI Ss (.08) indicating

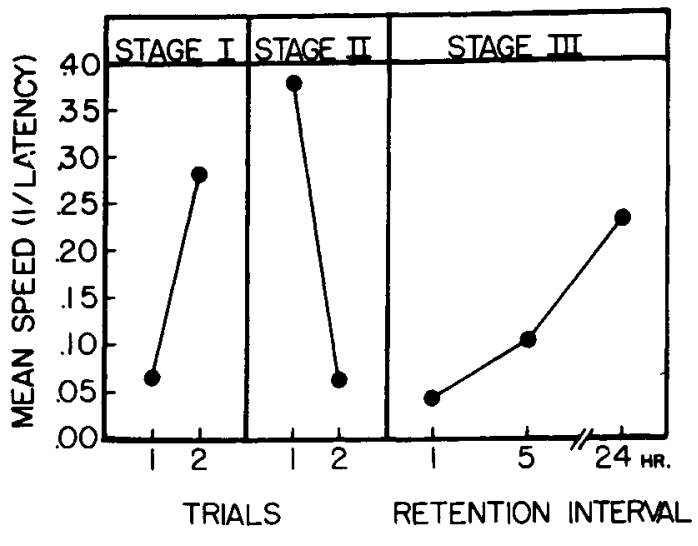

(MIN.)

Fig. 1. Mean speed on the first two trials of Stages 1 and 2, and mean speed as a function of retention interval in Stage 3. 


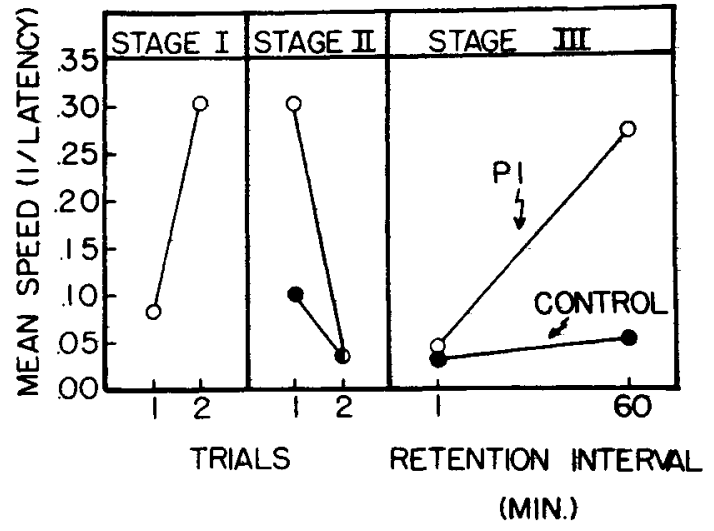

Fig. 2. Mean speed of PI Ss in Stage 1 and of PI and control Ss in Stage 2. Speed as a function of retention interval is shown for PI and control Ss in Stage 3.

that quinine exerts no suppressing influence until it is tasted.

The retention data are presented in the right panel of Fig. 2. The PI curve rose from a mean speed of .04 for the 1 -min group to .27 for the $60-\mathrm{min}$ group, while the control curve changed from .03 to .05 . This interaction was reliable $(F=26.8, \mathrm{df}=1.28$. $p<.01)$ indicating that there was little forgetting of Stage 2 reinforcer unless Ss had prior experience eating plain wet mash in the apparatus.

Discussion. The present results. expecially those of Experiment 2 provide a demonstration of $\mathrm{PI}$ in a simple, nondiscriminative learning situation. Furthermore. the occurrence of PI in Experiment 2 is purticularly interesting because of the relatively brief time intervals required to produce the effect. In fact, the intervals employed in Experiments 1 and 2 are easily comparable to those employed in typical demonstrations of spontaneous recovery. Thus, the present retention results appear to lend some support to the interpretation that (a) learned tendencies suppressed during the learning of subsequent events (reinforcer characteristics, perhaps) recover with time to interfere with retention of the second event; and (b) the underlying processes may be linked with the classical phenomenon, spontaneous recovery. Of course, processes involved in forgetting nondiscriminative tasks may be different than those involved in discriminative tasks, so the generality of the present conclusions remains a matter for future research.

\section{REFERENCES}

CHISZAR, D. A., \& SPEAR, N. E. Proactive interference in a $T$ maze brightness-discrimination task. Psychon. Sci., 1968, 11, 107-108.

KIMBLE, G. A. Hilgard and Marquis' conditioning and learning. New York: Appleton-Century-Crofts, 1961. Chap. 3.

KOPPENAAL, R. J., \& JAGODA, E. Proactive inhibition of a maze position habit. Paper read at meetings of the Eastern Psychological Association, Boston, 1967.

MAIER, S. F., \& GLEITMAN, H. Proactive interference in rats. Psychon. Sci., $1967,7,25-26$.

SPEAR, N. E. Retention of reinforcer magnitude. Psychol. Rev., 1967, 74, 216-234.

SPEAR, N. E., HILL, W. F., \& O'SUlliVAN, D. J. Acquisition and extinction after initial trials without reward. J. exp. Psychol., 1965, 69, 25-29.

SPEAR. N. E.. \& SPITZNER, J. H. Residual effects of reinforcer magnitude. J. exp. Psychol., 1968, 77. 135-149.

\section{NOTES}

1. This research was supported by United States Public Health Service Grant MH-12064 from the National Institute of Mental Health

2. United States Public Health Service Predoctoral Fellow. 